\title{
Development of Bulk InAsSb Alloys and Barrier Heterostructures for Long-Wave Infrared Detectors
}

\author{
YOUXI LIN,${ }^{1,3}$ DMITRY DONETSKY, ${ }^{1}$ DING WANG ${ }^{1}$ \\ DAVID WESTERFELD ${ }^{1}$ GELA KIPSHIDZE,${ }^{1}$ LEON SHTERENGAS,${ }^{1}$ \\ WENDY L. SARNEY, ${ }^{2}$ STEFAN P. SVENSSON ${ }^{2}$ \\ and GREGORY BELENKY ${ }^{1}$
}

\begin{abstract}
1.-Department of ECE, Stony Brook University, Stony Brook, NY 11794, USA. 2.-US Army Research Laboratory, 2800 Powder Mill Rd, Adelphi, MD 20783, USA. 3.-e-mail: youxi.lin@stonybrook.edu
\end{abstract}

Bulk unrelaxed InAsSb alloys with Sb compositions up to $65 \%$ were grown on compositionally graded GaInSb and AlInSb buffers on GaSb substrates by molecular beam epitaxy. The minimum energy gap for these materials at $T=77 \mathrm{~K}$ was estimated to be $90 \mathrm{meV}$. Benchmark material parameters were measured for barrier photodetector heterostructures with 1- $\mu \mathrm{m}$-thick InAs ${ }_{0.6} \mathrm{Sb}_{0.4}$ absorbers. A minority hole lifetime of $185 \mathrm{~ns}$ and a diffusion length of $9 \mu \mathrm{m}$ at $T=77 \mathrm{~K}$ were determined from the transient response of barrier heterostructures. The data imply a hole mobility of $10^{3} \mathrm{~cm}^{2} / \mathrm{Vs}$, which was confirmed with frequency response measurements. A $100-\mu \mathrm{m}$ square mesa contact $\mathrm{nBn}$ heterostructure demonstrated a $-3 \mathrm{~dB}$ frequency response bandwidth of $50 \mathrm{MHz}$.

Key words: InAsSb, energy gap bowing, long-wave infrared, barrier photodetector

\section{INTRODUCTION}

The development of InSb and InAs alloys for infrared photodetectors has a long history. ${ }^{1-4}$ Strong energy gap bowing in bulk InAsSb results in low energy gaps which are considerably smaller than those of the binaries. A $0.67 \mathrm{eV}$ energy gap bowing parameter was predicted based on the data compiled and reported in $2001 .^{5}$ This would result in a minimum low-temperature energy gap of $0.15 \mathrm{eV}$ $(\lambda=8.3 \mu \mathrm{m})$ at $63 \% \mathrm{Sb}$ composition. Smaller energy gaps with InAsSb-based materials were achieved with ordered alloys and superlattices. ${ }^{6}$ Recently, the authors of this paper developed bulk InAsSb alloys with $\mathrm{Sb}$ compositions up to $46 \%$, grown unrelaxed with low residual strain on compositionally graded GaInSb and AlInSb buffers on GaSb substrates. ${ }^{7,8}$ InAsSb alloys with $40 \% \mathrm{Sb}$ showed the photoluminescence (PL) maximum at an energy of $0.12 \mathrm{eV}$.

(Received February 22, 2015; accepted June 7, 2015;

published online June 19, 2015)
The PL width of a $14 \mathrm{meV}$ full-width at half-maximum at $T=13 \mathrm{~K}$ indicated high structural quality. A parabolic fit of the entire PL dataset for unstrained $\mathrm{InAsSb}$ at $T=13 \mathrm{~K}$ was obtained with a bowing parameter value of $0.87 \mathrm{eV}$, which is significantly larger than expected from Ref. 5. Electron diffraction patterns of unstrained InAsSb alloys showed a random (ordering-free) distribution of group V elements. ${ }^{8}$ Thus, the observed energy gaps of the alloys are inherent, and were not due to CuPttype ordering or residual strain effects. In InAsSb alloys with $40 \% \mathrm{Sb}$ at $T=77 \mathrm{~K}$, the background electron concentrations were as low as $1.5 \times$ $10^{15} \mathrm{~cm}^{-3}$. It is possible that the low energy gap data in earlier reports were masked by electron filling of the conduction band, which would be due to background doping as these samples were grown with various degrees of residual strain and relaxation. ${ }^{10}$ Residual strain in itself is also expected to increase the bandgap. In the present work, strainfree InAsSb alloys with an extended range of $\mathrm{Sb}$ compositions up to $65 \%$ were developed. The 
minimum energy gap of $90 \mathrm{meV}$ at $T=77 \mathrm{~K}$ was determined experimentally for InAsSb alloys with $\mathrm{Sb}$ compositions in the range of $55 \%$ to $65 \%$. For InAsSb with a 50\% Sb composition, the absorption coefficient was $5 \times 10^{3} \mathrm{~cm}^{-1}$ at $\lambda=8 \mu \mathrm{m}$.

For long-wave infrared (LWIR) applications, bulk InAsSb alloys have important materials advantages relative to Ga-free type 2 strained-layer superlattices (SLS), specifically greater fundamental absorption and unimpeded hole transport. The former feature implies greater photodetector quantum efficiency for a given absorber thickness. ${ }^{11,12}$ The latter is important for efficient collection of minority holes in photodetectors with $n$-type absorbers. ${ }^{13}$ Earlier we reported ${ }^{14,15}$ minority carrier lifetime values of $350 \mathrm{~ns}$ and $165 \mathrm{~ns}$ at $T=77 \mathrm{~K}$ for bulk InAsSb with $20 \%$ and $40 \% \mathrm{Sb}$, respectively. Since very little optimization of InAsSb has been done, it is likely that further improvements in lifetime properties can be achieved. Thus, bulk $n$-type InAsSb alloys are a promising III-V analogue of $n$-type $\mathrm{HgCdTe}$, which is the current state-of-theart material for LWIR detectors. InAs and InAs-like materials exhibit pinning of the Fermi level in the conduction band at the surface, and therefore show surface conduction by electrons. ${ }^{9}$ However, the ability to grow AlInAsSb barriers lattice-matched to InAsSb with low valence band offset at the interface makes it logical to implement LWIR detectors with a InAsSb bulk absorber following the $\mathrm{nBn}$ approach. ${ }^{16-18}$

LWIR barrier detectors based on bulk InAsSb with $40 \%$ Sb were reported previously. ${ }^{19}$ In this work, similar heterostructures were developed with Te-doped absorbers and modified barrier composition aimed at reducing valence band discontinuity as described in Ref. 15. A minority hole lifetime of $185 \mathrm{~ns}$ and a diffusion length of $9 \mu \mathrm{m}$ at $T=77 \mathrm{~K}$ for InAsSb with $40 \% \mathrm{Sb}$ was determined from the transient response characteristics of barrier heterostructures. The minority hole mobility was calculated to be $10^{3} \mathrm{~cm}^{2} / \mathrm{Vs}$. At $T=77 \mathrm{~K}$ and a bias voltage of $-0.4 \mathrm{~V}$ the devices with absorbers doped to a nominal level of $10^{16} \mathrm{~cm}^{-3}$ showed a dark current density of $10^{-5} \mathrm{~A} / \mathrm{cm}^{2}$. The quantum efficiency (QE) and dark current data for uncoated devices with $1-\mu$ m-thick undoped absorbers imply a $D^{*}=$ $2 \times 10^{11} \mathrm{cmHz}^{1 / 2} / \mathrm{W}$ at $\lambda=8 \mu \mathrm{m}$. Devices with a mesa contact area of $100 \mu \mathrm{m} \times 100 \mu \mathrm{m}$ showed a frequency response cutoff of $50 \mathrm{MHz}$.

\section{GROWTH AND OPTICAL CHARACTERIZATION OF INASSB ALLOYS}

The heterostructures were grown by solid-source molecular beam epitaxy (MBE) on GaSb substrates utilizing valved crackers for As and Sb. GaInSb and AlInSb buffers were grown by linearly increasing the In composition. The rate of increase of the lattice constant was in the range of $0.5 \% / \mu \mathrm{m}$ to $0.8 \% / \mu \mathrm{m}$. The graded buffer had a total thickness of up to
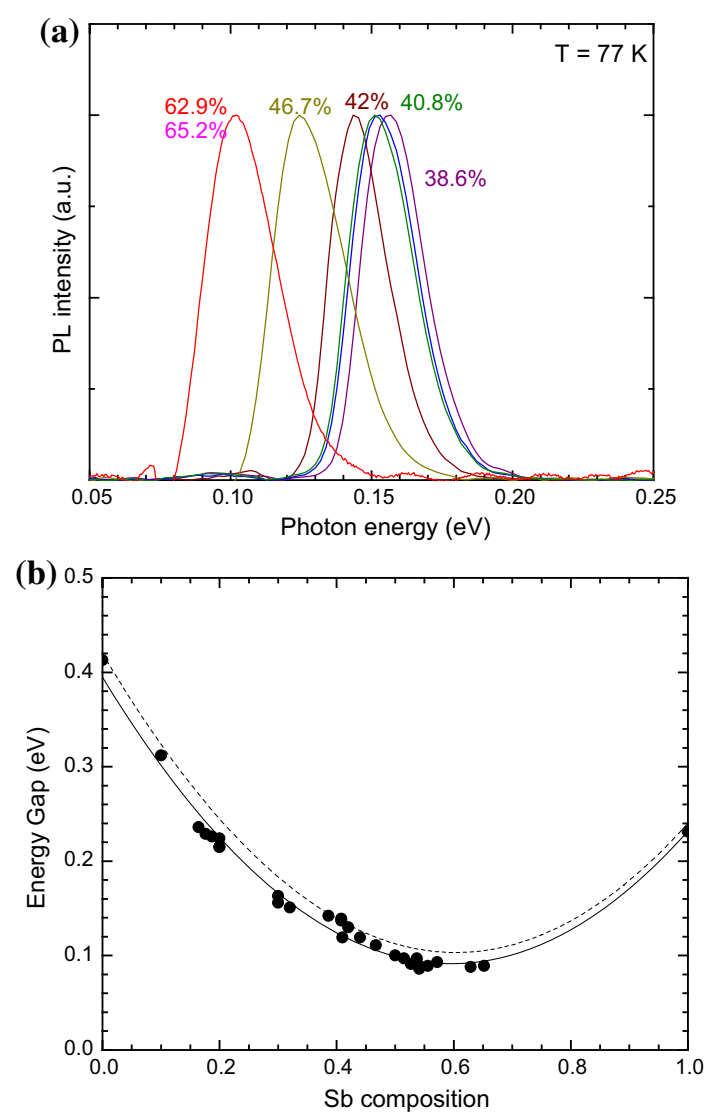

Fig. 1. (a) Normalized PL spectra of bulk InAsSb measured at $T=77 \mathrm{~K}$; numbers indicate $\mathrm{Sb}$ compositions. (b) Dependence of energy gap of InAsSb on Sb composition at $T=77 \mathrm{~K}$; energy gap values (dots and solid line fit) were obtained by subtraction of $2 k_{\mathrm{B}} T / e$ from the energy of PL maxima (dashed line fit). The best fit was obtained with a bowing parameter of $0.87 \mathrm{eV}$.

$3.5 \mu \mathrm{m}$. The buffer was relaxed except for the topmost section, which remained under a small compressive strain. ${ }^{4}$ The in-plane lattice constant of the top section of the buffer was determined by $\mathrm{x}$-ray diffraction (XRD) with reciprocal-space mapping. The unstrained and unrelaxed InAsSb layers were grown lattice-matched to the top of the buffer layer. The Sb incorporation was adjusted by changing the relative pressures of $\mathrm{As}$ and $\mathrm{Sb}$, as measured by a beam flux monitor. The growth rate was about $1 \mu \mathrm{m}$ per hour at a substrate temperature of $415^{\circ} \mathrm{C}$. Electron diffraction patterns showed no evidence of long-range CuPt-type ordering. ${ }^{8}$

PL spectra were measured with a Fourier-transform infrared (FTIR) spectrometer equipped with a HgCdTe detector with a $14 \mu \mathrm{m}$ cutoff wavelength. The PL was excited by a 1064-nm solid-state laser with a power of $100 \mathrm{~mW}$. The excitation area was $1.2 \times 10^{-3} \mathrm{~cm}^{2}$. Figure 1a shows the normalized PL spectra of the bulk InAsSb alloys with different $\mathrm{Sb}$ compositions measured at $T=77 \mathrm{~K}$. At this temperature the energy gaps of the alloys were determined by subtraction of $2 k_{\mathrm{B}} T$ from the PL maxima 


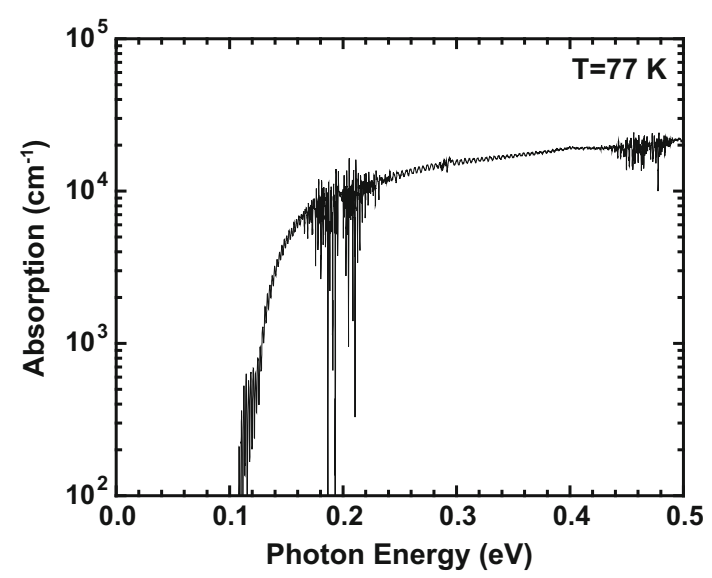

Fig. 2. Absorption spectrum of $\ln A s_{0.5} S_{0.5}$ at $T=77 \mathrm{~K}$.

to account for the effects of peak broadening with temperature. $^{20}$ The dashed line in Fig. $1 \mathrm{~b}$ shows the fit of the PL maxima. The best parabolic fit for the energy gap dependence on Sb composition (solid line in Fig. 1b) was obtained for a bowing parameter of $0.87 \mathrm{eV} .^{8,20}$

The absorption spectrum for InAsSb with a $50 \%$ $\mathrm{Sb}$ composition (Fig. 2) was obtained from the transparency spectra of the heterostructure and from the same wafer with the epilayer polished off. At a photon energy of $0.155 \mathrm{eV}(\lambda=8 \mu \mathrm{m})$ the absorption coefficient for $\operatorname{InAs_{0.5}} \mathrm{Sb}_{0.5}$ was found to be $5 \times 10^{3} \mathrm{~cm}^{-1}$.

\section{DESCRIPTION OF THE PHOTODETECTOR HETEROSTRUCTURES AND THE EXPERIMENTAL SETUP}

Figure $3 \mathrm{a}$ and $\mathrm{b}$ show the layer sequence and schematic band diagram of the barrier photodetector with an $\operatorname{InAs}_{0.6} \mathrm{Sb}_{0.4}$ absorber, respectively. The heterostructure consisted of the following sequence of layers: a 3- $\mu$ m-thick GaInSb buffer with the In composition linearly graded from $0 \%$ to $44 \%$, a 200 nm-thick GaInSb virtual substrate with $34 \%$ In composition (unstrained layer), a 1- $\mu \mathrm{m}$-thick InAs $\mathrm{As}_{0.6} \mathrm{Sb}_{0.4}$ absorber, a 20-nm-thick $\mathrm{Al}_{0.6} \mathrm{In}_{0.4} \mathrm{As}_{0.1}$ $\mathrm{Sb}_{0.9}$ barrier, and a $20-\mathrm{nm} \mathrm{InAs} \mathrm{s}_{0.6} \mathrm{Sb}_{0.4}$ top contact layer. The buffer, the virtual substrate, and the top contact layers were Te-doped to a level of $10^{18} \mathrm{~cm}^{-3}$. The AlInAsSb barrier was undoped. Two types of absorber layers were used. The first device structure was grown with an undoped absorber. The background electron concentration for similarly grown undoped InAsSb with $40 \% \mathrm{Sb}$ was $1.5 \times$ $10^{15} \mathrm{~cm}^{-3}$. A second device structure was grown with the absorber doped with tellurium to a nominal level of $10^{16} \mathrm{~cm}^{-3}$. The device area was defined by square-shaped mesa contacts defined by reactiveion etching stopped at the barrier layer. The heterostructure with the undoped absorber was processed into devices of two types designed for illumination from the episide and the backside.
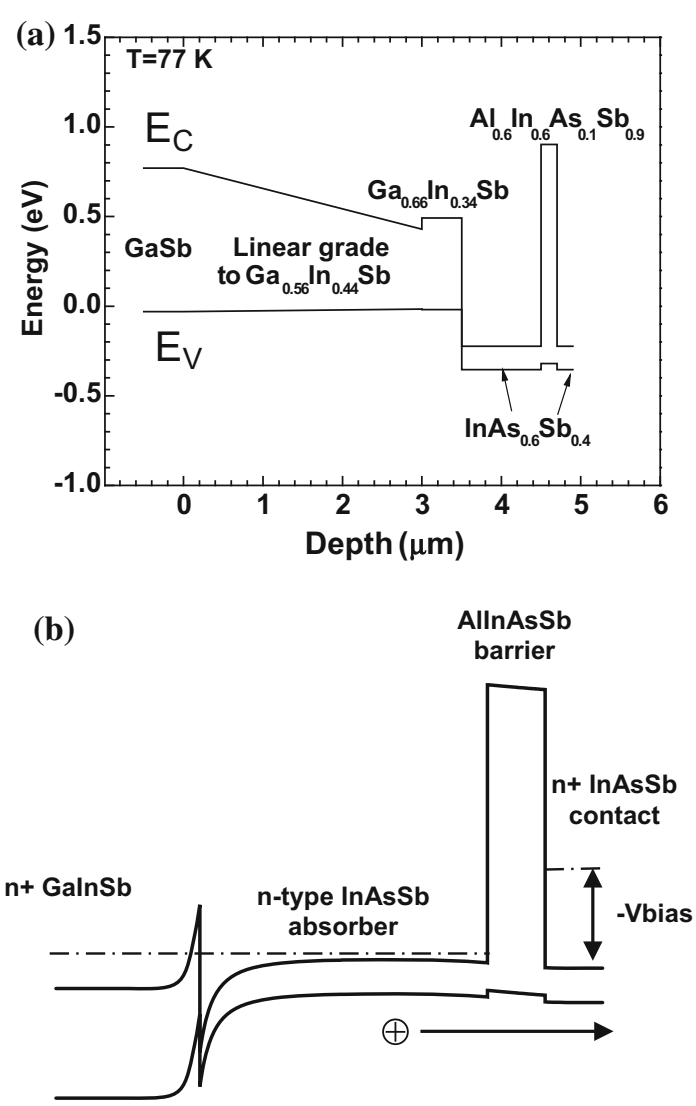

Fig. 3. Schematic band diagrams of the barrier detector heterostructure: (a) conduction and valence band energies; (b) energy band profile under the operating bias, the direction of the minority hole transport being shown with an arrow.

Both the episide- and backside-illuminated devices had mesa dimensions of $300 \mu \mathrm{m} \times 300 \mu \mathrm{m}$. The episide-illuminated devices had a window in the top metal with dimensions of $250 \mu \mathrm{m} \times 250 \mu \mathrm{m}$. The backside-illuminated devices had a $500 \mu \mathrm{m} \times$ $500 \mu \mathrm{m}$ window in the backside metal. For frequency response measurements, the heterostructure with the undoped absorber was processed for illumination from the episide with the mesa contact of $100 \mu \mathrm{m} \times$ $100 \mu \mathrm{m}$ and a $50 \mu \mathrm{m} \times 50 \mu \mathrm{m}$ window in the top metal. The heterostructure with the doped absorber was processed only for episide illumination with a mesa contact size of $300 \mu \mathrm{m} \times 300 \mu \mathrm{m}$ and a $250 \mu \mathrm{m} \times 250 \mu \mathrm{m}$ window in the top metal. Frontside electrical contact was made by wire bonding to a contact pad which was isolated from the epilayer with silicon nitride. The devices were soldered to a copper carrier.

The quantum efficiency (QE), dark current, and frequency response characteristics were obtained from the episide-illuminated devices. The diffusion length and the minority carrier lifetime were determined from the transient response characteristics. The diffusion length was determined with the backside-illuminated devices. The minority hole lifetime was obtained using both the episide- and 
backside-illuminated devices. All devices were uncoated.

The absolute values of the $\mathrm{QE}$ were obtained with an $800^{\circ} \mathrm{C}$ black-body source. The $\mathrm{QE}$ spectra were measured with a FTIR and HgCdTe photodetector with a cutoff wavelength of $14 \mu \mathrm{m}$. The transient responses were measured by illumination with a $\lambda=3.2 \mu \mathrm{m}$ diode laser at the trailing edge of the laser pulse. The laser was direct-current (DC) biased slightly below the threshold. The laser diode current was modulated with rectangular pulses with a $9 \mathrm{~ns}$ rise/fall time. The pulse duty cycle was varied in a range from $1 \%$ to $10 \%$. The laser power density was attenuated to a level of $0.1 \mathrm{~mW} / \mathrm{cm}^{2}$. The frequency response was measured with the $\lambda=8.6 \mu \mathrm{m}$ sine-wave modulated quantum cascade laser. The detectors were loaded with a preamplifier input resistance of $50 \Omega$. The preamplifier bandwidth was $80 \mathrm{MHz}$.

\section{EXPERIMENTAL RESULTS AND DISCUSSION}

The $\mathrm{nBn}$ device operated with a negative DC bias necessary for suppression of the barrier for minority hole transport to the top contact. Figure 4a shows the dependences of the $\mathrm{QE}$ on bias for the devices with undoped and doped absorber regions. For all devices a rapid increase of the $\mathrm{QE}$ with bias was observed in the range from $-0.25 \mathrm{~V}$ to $-0.4 \mathrm{~V}$. The measurements of QE spectra were conducted for the top-side-illuminated devices at a bias voltage of $-0.4 \mathrm{~V}$ with a spectral resolution of $4 \mathrm{~cm}^{-1}$ (Fig. $4 \mathrm{~b}$ ). The heavily doped top contact was essentially transparent for the long-wavelength emission. The $\mathrm{QE}$ increased monotonically from the long wavelength side up to a photon energy of $0.3 \mathrm{eV}$ $(\lambda \approx 4 \mu \mathrm{m})$. The distortions in the region between $\lambda=5.5 \mu \mathrm{m}$ and $7.5 \mu \mathrm{m}$ resulted from averaging the peaks of atmospheric absorption. The red-shift of the QE edge from $\lambda=10 \mu \mathrm{m}$ at $T=77 \mathrm{~K}$ to $\lambda=11 \mu \mathrm{m}$ at $T=150 \mathrm{~K}$ is explained by the decrease of the energy gap of InAsSb with temperature and consistent with the Varshni parameters we have determined earlier. $^{20}$ The absorber doping resulted in a blue-shift of the QE edge from $\lambda=10 \mu \mathrm{m}$ to $8.3 \mu \mathrm{m}$ at $T=77 \mathrm{~K}$ due to band filling. Considering reflection losses from the surface of the uncoated devices, and using the absorption coefficient estimate of $1.5 \times 10^{4} \mathrm{~cm}^{-1}$ (Fig. 2), and a 50\% QE in the range $\lambda=4 \mu \mathrm{m}$ to $5 \mu \mathrm{m}$, we find that most of the excess holes generated at $T=77 \mathrm{~K}$ to $150 \mathrm{~K}$ in the $1-\mu \mathrm{m}$-thick absorber reached the contact. Therefore, we conclude that the minority hole lifetime in $\mathrm{InAs}_{0.6} \mathrm{Sb}_{0.4}$ was significantly greater than the hole transport time across the device in the temperature range up to $150 \mathrm{~K}$ and with $n$-doping of the absorber up to the level of $10^{16} \mathrm{~cm}^{-3}$. A $22 \% \mathrm{QE}$ at $\lambda=8 \mu \mathrm{m}$ for $1-\mu \mathrm{m}$-thick InAs $\mathrm{As}_{0.6} \mathrm{Sb}_{0.4}$ implies an absorption coefficient of $3 \times 10^{3} \mathrm{~cm}^{-1}$, consistent with available experimental data. There is no surface leakage current contribution
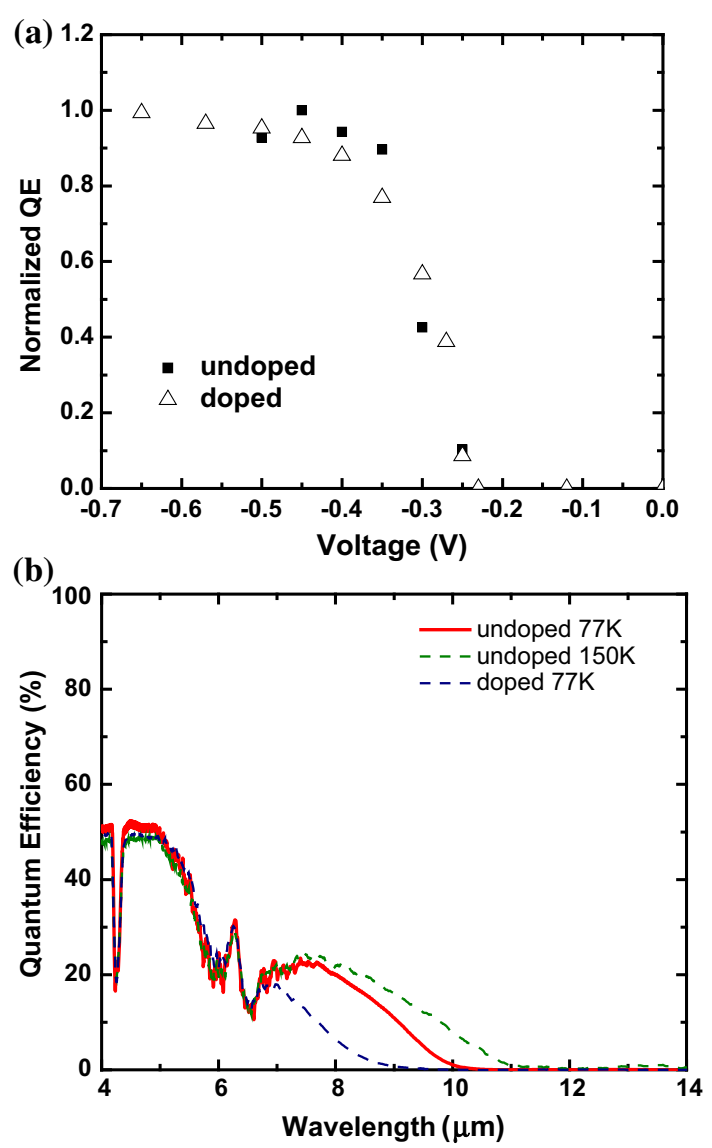

Fig. 4. (a) Dependences of integrated QE on bias voltage for $n B n$ photodetectors with undoped and doped $\ln \mathrm{As}_{0.6} \mathrm{Sb}_{0.4}$ absorbers at $T=77 \mathrm{~K}$; (b) QE spectra for $\mathrm{nBn}$ photodetectors with undoped absorber at $T=77 \mathrm{~K}$ and $150 \mathrm{~K}$ (solid and dotted lines, respectively) and for one with doped absorber at $T=77 \mathrm{~K}$ (dashed line). Spectra were measured at bias voltage of $-0.4 \mathrm{~V}$.

to the dark current, observed as the dark current was scaled with the mesa area. The dependences of the dark current density on voltage for the devices with undoped and doped absorbers are shown in Fig. 5a and b, respectively. A rapid increase of current in the range of $-0.15 \mathrm{~V}$ to $-0.25 \mathrm{~V}$ was attributed to suppression of the barrier for minority holes due to the difference in doping levels between the absorber and the contact regions. As mentioned, the $\mathrm{QE}$ data suggested that most minority holes were collected by the contact at the bias voltage of $-0.4 \mathrm{~V}$. At this bias, the devices with undoped and doped absorbers showed dark current densities of $10^{-3}$ $\mathrm{A} / \mathrm{cm}^{2}$ and $10^{-5} \mathrm{~A} / \mathrm{cm}^{2}$, respectively. Figure 5c shows the temperature dependences of the dark current for both devices at the bias voltages of $-0.4 \mathrm{~V}$ and $-0.5 \mathrm{~V}$. The prefactor $T^{3}$ accounts for the temperature dependence of the density of states. One can see that, for the devices with undoped absorbers, the dark current increases with change in the bias voltage from $-0.4 \mathrm{~V}$ to $-0.5 \mathrm{~V}$. Such behavior can be explained by depletion of a part of the absorber adjacent to the barrier, which leads to domination of 

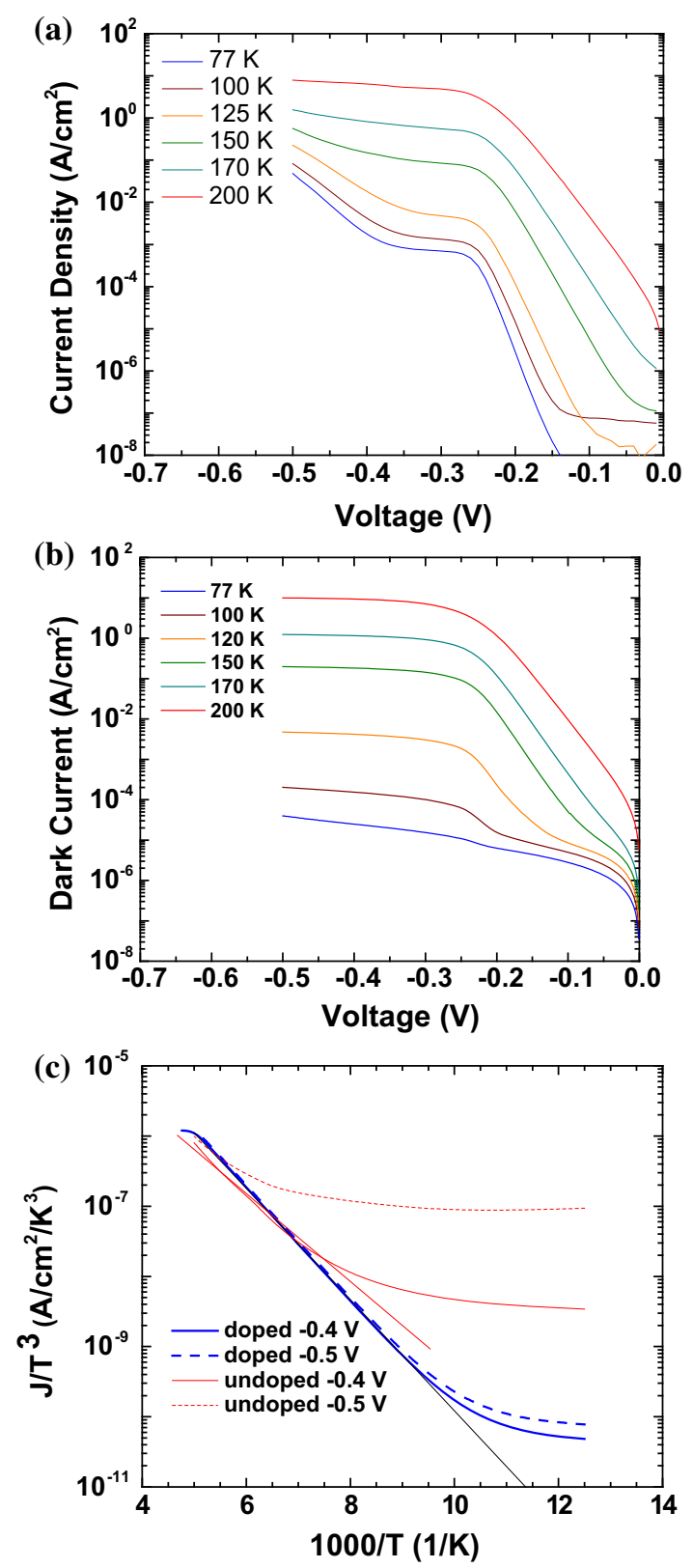

Fig. 5. Current-voltage characteristics of $n B n$ devices with undoped (a) and doped (b) $\ln \mathrm{As}_{0.6} \mathrm{Sb}_{0.4}$ absorbers at different temperatures. (c) Temperature dependences of dark current densities taken at bias voltages of $-0.4 \mathrm{~V}$ and $-0.5 \mathrm{~V}$ for undoped and doped devices, respectively.

the generation-recombination $(\mathrm{G}-\mathrm{R})$ and perhaps tunneling components at $T=77 \mathrm{~K}$. The depletion of the absorber resulted from the high bias necessary for suppression of the barrier for hole transport due to the valence band offset at the interface of the absorber and the barrier, as well as accumulation of electrons as shown in Ref. 9. For the devices with the doped absorber, the width of the depleted region was significantly reduced, which resulted in independence of the dark current from the bias in the temperature range above $T=110 \mathrm{~K}$. The activation energy of

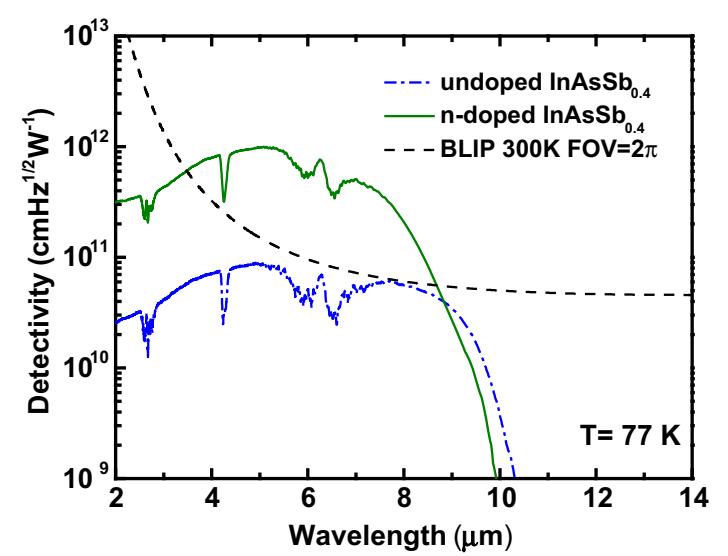

Fig. 6. Specific detectivity spectra of barrier detectors with $1-\mu \mathrm{m}$ thick $\operatorname{InAs} \mathrm{s}_{0.6} \mathrm{Sb}_{0.4}$ absorbers at $T=77 \mathrm{~K}$. Solid and dashed lines correspond to devices with doped and undoped absorbers, respectively. Dotted line shows the $300-\mathrm{K}$ background limit for a $2 \pi$ acceptance angle.

$153 \mathrm{meV}$ determined from the slope in the temperature range $T=110 \mathrm{~K}$ to $200 \mathrm{~K}$ is comparable to the energy gap. The difference can be explained by population of states in the conduction band with doping and the band nonparabolicity. Quantitative accounting for the latter lies beyond the scope of this work.

It should be noted that, in the devices cooled to $T=77 \mathrm{~K}$, the photocurrent was significantly greater than the dark current. This is due to exposure to both room-temperature background illumination and the attenuated laser emission. Under the experimental conditions the photocurrent was independent of bias and therefore exhibited the diffusion behavior. Thus, the minority hole transport in both transient and frequency response measurements was dominated by diffusion.

For assessment of the material properties related to infrared detection, the specific detectivity spectra (Fig. 6) were calculated for both devices at $T=77 \mathrm{~K}$ with the following equation ${ }^{21}$ :

$$
D^{*}=(e \lambda / h c \mathrm{QE}) / \sqrt{ }\left(2 e J+4 k_{\mathrm{B}} T / R A\right) .
$$

The dark current and the differential resistance were taken at a bias of $-0.4 \mathrm{~V}$. The nonoptimized devices with 1- $\mu \mathrm{m}$-thick absorbers showed performance exceeding the $300-\mathrm{K}$ background limit in a $2 \pi$ acceptance angle ${ }^{21}$ and demonstrated a $D^{*}=2 \times 10^{11}$ $\mathrm{cmHz}^{1 / 2} / \mathrm{W}$ at $\lambda=8 \mu \mathrm{m}$ in spite of the significant blue-shift of the absorption edge with doping.

The minority hole lifetime in $\mathrm{InAs}_{0.6} \mathrm{Sb}_{0.4}$ was determined from the transient response of the $\mathrm{nBn}$ devices to a pulsed excitation following the approach in Ref. 15. Excess carriers were excited through the window in the back metal contact. The excess holes in the absorbers were collected within a distance to the mesa contact limited by the diffusion length (Fig. 7a). From the QE data in Fig. 4b it was concluded that the minority carrier lifetime was greater than the hole transport time across the absorber. 

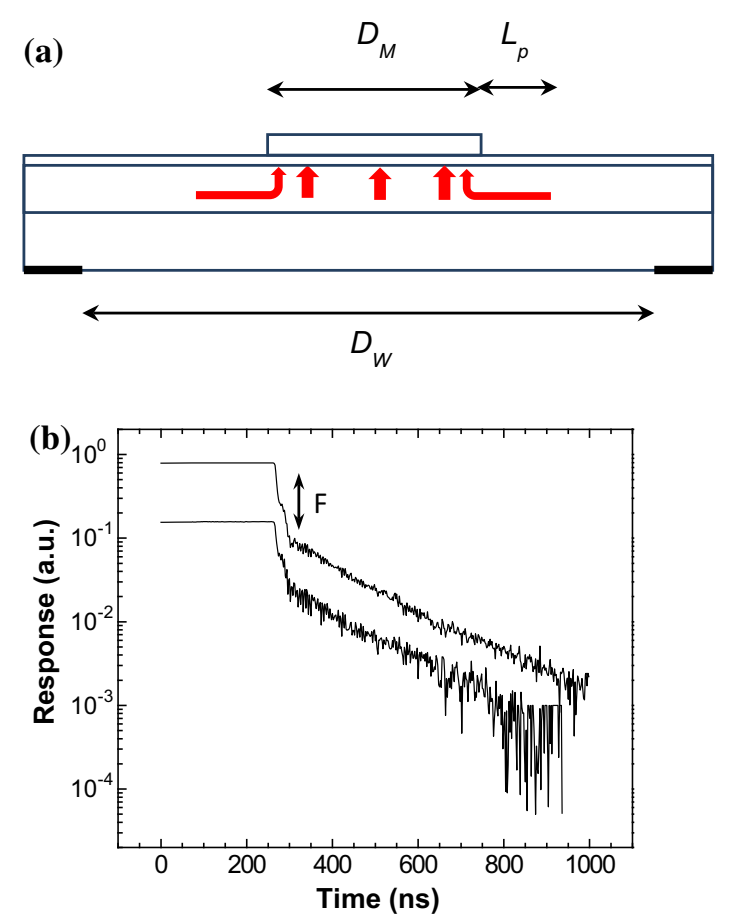

Fig. 7. (a) Schematic cross-section and top view of $\mathrm{nBn}$ heterostructure for determination of diffusion length and minority carrier lifetime of absorber. (b) Transient responses of $\mathrm{nBn}$ detectors with undoped absorbers for two excitation power densities. Transient responses were measured under a bias voltage of $-0.4 \mathrm{~V}$. The duty cycle was $10 \%$. Two curves correspond to different excitation intensities. The fast component of the response with the amplitude denoted by $F$ is followed by the slow component used for determination of the minority carrier lifetime.

This implies that the diffusion length of the minority carriers was greater than the absorber thickness. Under this condition the transient response of the device to a pulsed excitation showed two components with very different kinetics which allowed us to separate them: a fast component $(F)$, due to the vertical hole transport across the absorber, and a slow component $(S)$, due to the lateral diffusion of holes in the peripheral area of the mesa contact (Fig. 7b). This interpretation of the origin of both components of the response was confirmed in Ref. 15, where for heterostructures of various dimensions it was shown that the fast and slow components of the response vary in proportion to the area and the perimeter of the mesa contact. In the present work the minority hole diffusion length $L_{p}$ was determined using the ratio of the intensities of the fast and slow components of the response only for the heterostructure with mesa width $D_{\mathrm{M}}=300 \mu \mathrm{m}$.

$$
L_{p}=\frac{D_{\mathrm{M}}}{4 F / S} .
$$

The diffusion length for the undoped $\operatorname{InAs}_{0.6} \mathrm{Sb}_{0.4}$ was equal to $9 \mu \mathrm{m}$, consistent with the data reported earlier. ${ }^{15}$ The slow component of the response was used to determine the minority carrier lifetime $\tau_{p}$ by fitting the response to the following equation ${ }^{15}$ :

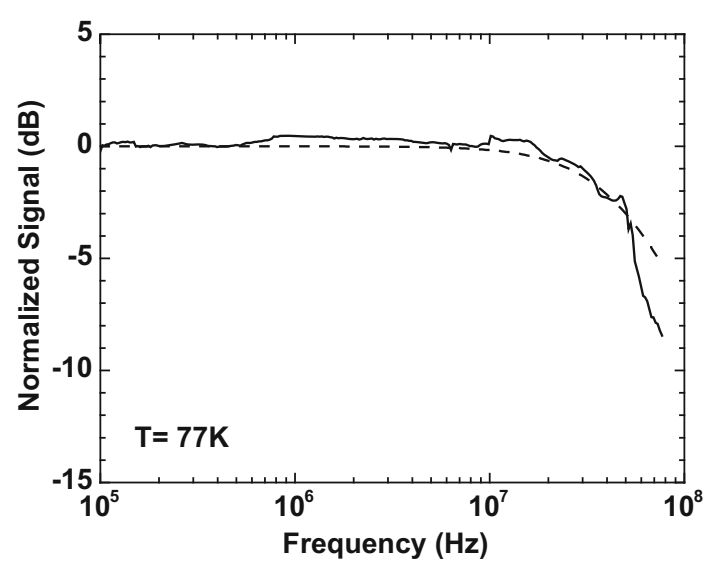

Fig. 8. Frequency response of $100-\mu \mathrm{m}$-mesa barrier detector measured with $\lambda=8.6 \mu \mathrm{m}$ quantum cascade laser. The dotted line is a fit with a single pole response.

$$
S \propto \exp \left(-\frac{t}{\tau_{p}}\right) \operatorname{Erf}\left(\frac{D_{\mathrm{W}}-D_{\mathrm{M}}}{4} \sqrt{\frac{\tau_{p}}{L_{p}^{2} t}},\right)
$$

where "Erf" is the error function. The two parameters, i.e., the minority carrier lifetime $\tau_{p}$ and diffusion length $L_{p}$, were determined from the response. For the undoped InAs $s_{0.6} \mathrm{Sb}_{0.4}$ a minority hole lifetime of $170 \mathrm{~ns}$ and a diffusion length of $9 \mu \mathrm{m}$ were obtained, consistent with and confirming the applicability of Eq. 2. A relatively long diffusion length suggested that most of the peripheral carrier collection area was not depleted, hence the minority holes from the peripheral area reached the contact by diffusion. Estimates showed that the role of the electric field in the lateral hole transport was negligible. A minority hole mobility of $10^{3} \mathrm{~cm}^{2} / \mathrm{Vs}$ was calculated using the Einstein relation.

The minority hole lifetime for the devices with $\mathrm{InAs}_{0.6} \mathrm{Sb}_{0.4}$ absorbers doped to the level of $10^{16} \mathrm{~cm}^{-3}$ was similarly determined using top-sideilluminated devices. The best fit for the slow component of the response was obtained with parameters similar to those for the devices with undoped absorbers: a $185 \mathrm{~ns}$ minority hole lifetime and a $9 \mu \mathrm{m}$ diffusion length at $T=77 \mathrm{~K}$. One can conclude that the minority hole lifetime in In$\mathrm{As}_{0.6} \mathrm{Sb}_{0.4}$ at $T=77 \mathrm{~K}$ in the range of $n$-doping up to the level of $10^{16} \mathrm{~cm}^{-3}$ is limited by Shockley-ReadHall recombination, and the contribution of Auger recombination at this temperature can be neglected.

Using the mobility data, the diffusion time of minority holes across the absorber was estimated to be less than 2 ns. Figure 8 shows the frequency response and the fitting for devices with undoped absorbers and mesa contact widths of $100 \mu \mathrm{m}$, obtained at $\lambda=8.6 \mu \mathrm{m}$.

The devices with the mesa contact width of $D_{\mathrm{M}}=100 \mu \mathrm{m}$ were illuminated from the episide through a window in the top metal with dimensions 
of $50 \mu \mathrm{m} \times 50 \mu \mathrm{m}$. Since the windows were smaller than the dimensions of the mesa contacts, the response time was defined by the vertical hole transport time and the device time constants. A cutoff frequency of $50 \mathrm{MHz}$ at a level of $-3 \mathrm{~dB}$ was obtained. It was concluded that the cutoff frequency was limited by the time constant formed by a $63 \mathrm{pF}$ capacitance of the device and input network and a $50 \Omega$ preamplifier input resistance.

\section{CONCLUSIONS}

Bulk InAsSb alloys free of group $\mathrm{V}$ ordering grown on metamorphic buffers have inherent bandgaps that span the LWIR range at low temperatures. Such alloys have greater fundamental absorption and unimpeded hole transport relative to Ga-free type 2 SLS structures, allowing greater photodetector $\mathrm{QE}$ for a given absorber thickness and the efficient collection of minority holes in the $n$-type absorber region.

In this study, bulk InAsSb was assessed with barrier heterostructures consisting of a $1-\mu \mathrm{m}$-thick InAs ${ }_{0.6} \mathrm{Sb}_{0.4}$ absorber with two doping levels. The $\mathrm{QE}$, dark current, and diffusion length data for the nonoptimized devices at $T=77 \mathrm{~K}$ imply a specific detectivity of $2 \times 10^{11} \mathrm{cmHz}^{1 / 2} / \mathrm{W}$ at $\lambda=8 \mu \mathrm{m}$. Material parameters were obtained from the transient response of the barrier heterostructures to a pulsed excitation. For $\operatorname{InAs}_{0.6} \mathrm{Sb}_{0.4}$ at $T=77 \mathrm{~K}$ it was found that the minority hole lifetime is limited by Shockley-Read-Hall recombination at $185 \mathrm{~ns}$ for $n$-type doping up to $10^{16} \mathrm{~cm}^{-3}$. The hole mobility of $10^{3} \mathrm{~cm}^{2} / \mathrm{Vs}$ was obtained from the lifetime and diffusion length data. The high mobility of minority holes was confirmed with frequency response measurements: a $50 \mathrm{MHz}$ bandwidth was demonstrated for $100 \mu \mathrm{m} \times 100 \mu \mathrm{m}$ mesa contact barrier heterostructures. The long diffusion length makes it possible to develop barrier heterostructures with much greater absorber thicknesses. At present, the dark currents of our bulk InAsSb/AlInSb nBn diodes at $77 \mathrm{~K}$ are not diffusion limited. In order to allow us to reach that level, the valance band offset associated with the heterointerfaces must be eliminated. Work to achieve this is ongoing and will be presented in future publications.

\section{ACKNOWLEDGEMENTS}

The work was supported by US Army Research Office through Award W911NF1220057 and by US National Science Foundation through Grant No. DMR1160843.

\section{REFERENCES}

1. G.C. Osbourn, J. Vac. Sci. Technol., B 2, 176 (1984).

2. G.S. Lee, Y. Lo, Y.F. Lin, S.M. Bedair, and W.D. Laidig, Appl. Phys. Lett. 47, 1219 (1985).

3. M.Y. Yen, B.F. Levine, C.G. Bethea, K.K. Choi, and A.Y. Cho, Appl. Phys. Lett. 50, 927 (1987).

4. L.R. Dawson, J. Vac. Sci. Technol., B 4, 598 (1986).

5. I. Vurgaftman, J.R. Meyer, and L.R. Ram-Mohan, J. Appl. Phys. 89, 5815 (2001).

6. S.R. Kurtz, L.R. Dawson, R.M. Biefeld, D.M. Follstaedt, and B.L. Doyle, Phys. Rev. B 46, 1909 (1992).

7. G. Belenky, D. Donetsky, G. Kipshidze, D. Wang, L. Shterengas, W.L. Sarney, and S.P. Svensson, Appl. Phys. Lett. 99, 141116 (2011).

8. S.P. Svensson, W.L. Sarney, H. Hier, Y. Lin, D. Wang, D. Donetsky, L. Shterengas, G. Kipshidze, and G. Belenky, Phys. Rev. B 86, 245205 (2012).

9. S.P. Svensson, F. Crowne, H. Hier, W.L. Sarney, W. Beck, Y. Lin, D. Donetski, S. Suchalkin, and G. Belenky, Semicond. Sci. Technol. 30, 035018 (2015).

10. Z.M. Fang, K.Y. Ma, D.H. Jaw, R.M. Cohen, and G.B. Stringfellow, J. Appl. Phys. 67, 7034 (1990).

11. P.C. Klipstein, Y. Livneh, A. Glozman, S. Grossman, O. Klin, N. Snapi, and E. Weiss, J. Electron. Mater. 43, 2984 (2014).

12. Y. Livneh, P.C. Klipstein, O. Klin, N. Snapi, S. Grossman, A. Glozman, and E. Weiss, Phys. Rev. B 86, 235311 (2012).

13. B.V. Olson, E.A. Shaner, J.K. Kim, J.F. Klem, S.D. Hawkins, L.M. Murray, J.P. Prineas, M.E. Flatté, and T.F. Boggess, Appl. Phys. Lett. 101, 092109 (2012).

14. D. Wang, Y. Lin, D. Donetsky, L. Shterengas, G. Kipshidze, G. Belenky, W.L. Sarney, H. Hier, and S.P. Svensson, Infrared Technology and Applications, XXXVIII, ed. B.J. Andresen, G.F. Fulop, P.R. Norton, Proc. of SPIE, 8353, 835312 (2012).

15. Y. Lin, D. Wang, D. Donetsky. G. Kipshidze, L. Shterengas, L.E. Vorobjev, and G. Belenky, Semicond. Sci. Technol. 29, $112002(2014)$.

16. S. Maimon and G.W. Wicks, Appl. Phys. Lett. 89, 151109 (2006).

17. P.C. Klipstein, Infrared Technology and Applications, XXXIV, ed. B.J. Andresen, G.F. Fulop, P.R. Norton, Proc. of SPIE, 6940, 694002U (2008).

18. P.C. Klipstein, U.S. Patent 7.795.640 (2003).

19. D. Wang, D. Donetsky, G. Kipshidze, Y. Lin, L. Shterengas, G. Belenky, W.L. Sarney, and S.P. Svensson, Appl. Phys. Lett. 103, 051120 (2013).

20. Y. Lin, D. Wang, D. Donetsky, L. Shterengas, G. Kipshidze, G. Belenky, S.P. Svensson, W.L. Sarney, and H.S. Hier, J. Electron. Mater. 42, 918 (2012).

21. A. Rogalski, Infrared Detectors, 2nd ed. (Boca Raton: Taylor \& Francis, 2010). 